\title{
A Case of Bilateral Peripheral Ulcerative Keratitis
}

\author{
Belghmaidi Sarah", Darfaoui Zineb, Hajji Ibtissam, Moutaouakil Abdeljalil \\ Ophtalmology Department, Mohammed VI University Hospital, Marrakech, Morocco

\section{Email address:} \\ sarahhhbelgh@gmail.com (B. Sarah), darfaouiiizineb@gmail.com (D. Zineb), Ib.hajji@gmail.com (H. Ibtissam), \\ moutaouakilabdeljalil@yahoo.fr (M. Abdeljalil) \\ ${ }^{*}$ Corresponding author
}

\section{To cite this article:}

Belghmaidi Sarah, Darfaoui Zineb, Hajji Ibtissam, Moutaouakil Abdeljalil. A Case of Bilateral Peripheral Ulcerative Keratitis. International Journal of Ophthalmology \& Visual Science. Vol. 6, No. 2, 2021, pp. 150-153. doi: 10.11648/j.ijovs.20210602.23

Received: May 31, 2021; Accepted: June 15, 2021; Published: June 30, 2021

\begin{abstract}
Peripheral ulcerative keratitis (PUK) is an aggressive, potentially sight-threatening cause for peripheral corneal thinning. It may precede the diagnosis of the systemic condition and therefore these cases require urgent investigation. A 43year-old woman presented with bilateral tearing and ocular pain persisting for 7 months. Visual acuity was $6 / 6$ in both eyes. On biomicroscopic examination, presence of crescent shaped corneal ulcer with perilesional haziness. A tear film study demonstrated decreased Schirmer test results ( $5 \mathrm{~mm}$ in both eyes) and tear film break-up time (5 sec in both eyes). The interrogation and the patient revealed he had recurrent skin lesions in both legs with chronic itching, and recurrent oral and genital ulcers healing spontaneously. The diagnosis of Behcet disease was proposed. Pathergy test was negative, HLA B51 was positif. Systemic therapy was started with colchicine at a dose of $2 \mathrm{mg} / \mathrm{day}$. Eye drops and systemic prednisolone at $1 \mathrm{mg} / \mathrm{kg} / \mathrm{day}$ was continued with progressive decrease. The follow up at 3 months and 6 months showed no signs of recurrence of ulceration in both eyes. Corneal manifestation has rarely been reported in Behçet's disease. Combined intraocular anterior and posterior segment inflammation are most common features of ocular Behçet disease. Collaborative management of ophthalmic patients having systemic illness along with internists improves overall outcomes and prevents morbidity in such patients.
\end{abstract}

Keywords: Ocular Inflammation, Corneal Ulcer, Amniotic Membrane, Behcet Disease, PUK

\section{Introduction}

Peripheral ulcerative keratitis (PUK) is an aggressive, potentially sight-threatening cause for peripheral corneal thinning [1]. It involves crescent-shaped corneal ulcers adjacent to the limbus. Epithelial defects may occur over areas of corneal stromal thinning, adjacent scleral and conjunctival involvement may occur [2]. It is thought to be the result of immune complex deposition in the limbus, resulting corneal inflammation. If left untreated, it can lead to corneal perforation and loss of vision. PUK may be the presenting feature of a potentially life-threatening systemic disease. Systemic causes may be infectious or non-infectious. PUK may precede the diagnosis of the systemic condition and therefore these cases require urgent investigation [1]. generally, PUK appears late and usually signals worsening of a systemic disease [3]. Its principal cause is Rheumatoid arthritis which can be found in $34-42 \%$ of PUK patients [4].

\section{Case Presentation}

Here we describe the clinical case of a female patient, who was 43 years old at initial visit at our department. She presented with bilateral tearing and ocular pain persisting for 7 months. The patient had no operations or any ocular diseases in the past medical history. The patient had no internal diseases and did not take any drugs in the last months.

At the initial examination, the corrected visual acuity was $6 / 6$ in both eyes. In the right eye, slit-lamp examination showed mild conjunctival hyperemia and an inferior crescent-shaped corneal ulcer with limbal involvement but no associated scleritis (figure 1). In the left eye, slit-lamp examination showed mild conjunctival hyperemia and a superior crescent-shaped corneal ulcer with limbal involvement but no associated scleritis (figure 2). In both eyes, there was perilesional haziness and the fluorescein stain was positive (indicating overlying epithelial defect). Also, in 
both eyes, there was no sign of corneal infection (purulent secretions or infiltrates), corneal sensitivity was preserved. A tear film study demonstrated decreased Schirmer test results ( $5 \mathrm{~mm}$ in both eyes) and tear film break-up time ( $5 \mathrm{sec}$ in both eyes). There was no inflammatory reaction in the anterior chamber and no signs of retinal vasculitis.

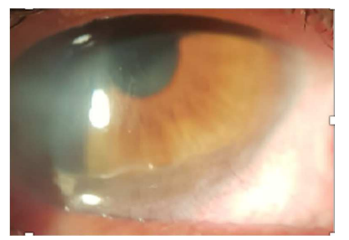

Figure 1. Inferior crescent-shaped corneal ulcer with limbal involvement but no associated scleritis.

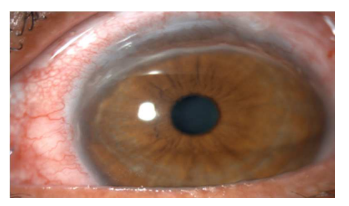

Figure 2. Superior crescent-shaped corneal ulcer with limbal involvement but no associated scleritis, and with fluorescein stain positive.

Systemic evaluation for underlying diseases causing peripheral ulcerative keratitis included: Complete Blood Count (CBC), complete Metabolic Profile (CMP), urinalysis with microscopic analysis, infectious serology, angiotensin converting enzyme (ACE), X-ray chest and joints, accessory salivary gland biopsies and autoimmune screenings (for rheumatoid factor, antinuclear antibody, anti-neutrophil cytoplasmic antibody and anti-DNA antibody).

The patient was treated topically with $1 \%$ prednisolone acetate six times a day, $0,3 \%$ sodium hyaluronate frequently and oral systemic prednisolone at $1 \mathrm{mg} / \mathrm{kg}$ /day for 15 days.

The patient observed an increased pain and redness in both eyes. The slit-lamp examination revealed a deep corneal ulcer. Amniotic membrane transplantation with conjunctival resection was done in the area of melt were done in both eyes (to fill the corneal defect and to promote the corneal cicatrization) (figure 3,4 ).

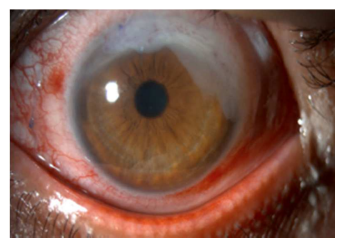

Figure 3. Amniotic membrane transplantation for the corneal ulcer in the left eye

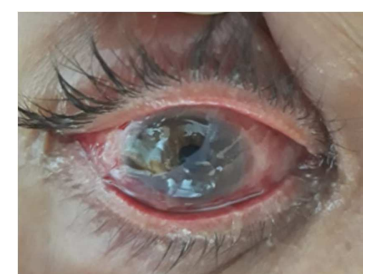

Figure 4. Amniotic membrane transplantation overlay technique for the corneal ulcer in the right eye.
Nevertheless, the amniotic membrane was rapidly reduced without corneal reconstruction or healing and there was circumferential thinning which was progressing in both eyes (figure 5).

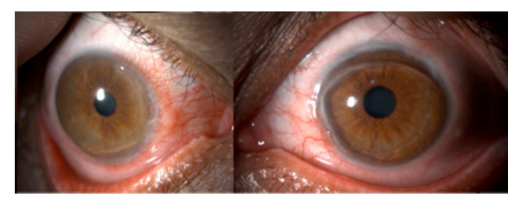

Figure 5. Resorption of the amniotic membrane in both eyes, and the progressing of the $P U K$.

The patients ocular symptoms kept on worsening which led to the supposition that we missed the diagnosis. So, we went back to the interrogation and the patient revealed he had recurrent skin lesions in both legs with chronic itching, and recurrent oral and genital ulcers healing spontaneously.

We supposed a possible diagnosis could be Behcet's disease. A further assessment was requested to confirm the diagnosis of Behçet; Pathergy test was negative (figure 6), HLA B51 was positif. And following international diagnostic criteria for Behçet's Disease, we kept the diagnosis of Behçet. Systemic therapy was started with colchicine at a dose of $2 \mathrm{mg} /$ day. Eye drops and systemic prednisolone at $1 \mathrm{mg} / \mathrm{kg} /$ day was continued with progressive decrease.

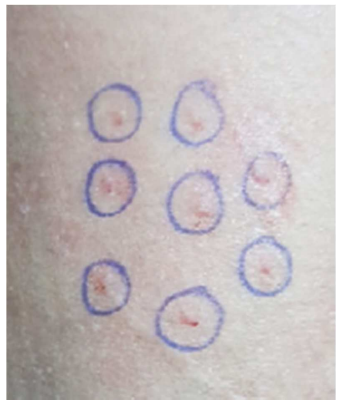

Figure 6. Negative pathergy test after 72 hours.

After 2 weeks, the ocular pain was relieved and the conjunctival hyperemia improved. At 1 month of treatment, symptoms were absent. The corrected visual acuity was $10 / 10$ in both eyes. Slit-lamp examination showed healed corneal lesion with stromal thinning and mild haziness (figure 7).

The follow up at 3 months and 6 months showed no signs of recurrence of ulceration in both eyes.

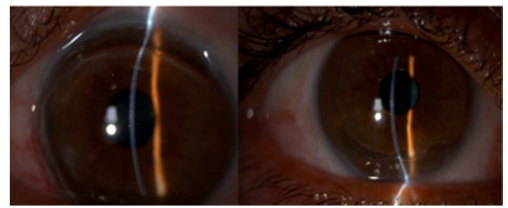

Figure 7. Healed corneal ulceration with stromal thinning and mild haziness.

\section{Discussion}

Behçet's syndrome (BS), also called Behçet's disease, was 
first described by famous Turkish dermatologist Hulusi Behçet in 1937 [5]. BS has been accepted as a multi systemic vasculitis involving, skin, mucosa, eyes, joints, nervous system, cardiovascular system and gastrointestinal system [6]. It is remarkable that vasculitis in BS can involve any kind and size of vessels, and this explains why the disease has the ability of multi systemic involvement [7]. BS may mimic many diseases with its several faces and can be considered as one of the great imitators [5].

Corneal manifestation has rarely been reported in Behçet's disease [8-10]. The patient often presents to ophthalmologist first. Combined intraocular anterior and posterior segment inflammation $(89,9 \%-95,4 \%)$ are most common features of ocular Behçet disease [11]. However, ocular surface involvement in the form of conjunctival follicular reaction and, conjunctival ulceration has been noted and none of these patients had intraocular inflammation [11, 12]. Zeng and Chen [11] described a case of ocular surface involvement in BS with severe dry eye syndrome, symblepharon, granulation- like tissue proliferation in conjunctiva, and peripheral corneal ulceration, without intraocular inflammation. Yong-Sok Ji [9] reported a case of unilateral peripheral ulcerative keratitis in a patient who had been treated for previously diagnosed Behçet's disease. Our case contrasted in clinical presentation as it presented with peripheral ulcerative keratitis which progressed rapidly to involve corneal stroma, under systemic steroid and local prednisolone. Therefore, we have reconsidered our diagnosis and further evaluation was requested.

This current case suggests that despite its rare occurrence, peripheral ulcerative keratitis can develop in Behçet's disease. Hence, patients presenting PUK require examination for Behçet's disease using a systemic evaluation, and HLAB51 has to be included in the biological assessment.

\section{Conclusion}

Diagnoses in ocular surface disease are very challenging as different diseases can present initially similar symptoms. Peripheral ulcerative keratitis is typical for several autoimmune diseases but can also be seen in infecions.

In clinical cases with fast progressive clinical manifestations, as presented here, the natural evolution in weeks or even months is unavoidable, and it's the corneal perforation.

An early systemic evaluation after ruling out infectious causes is needed in every case of PUK.

Collaborative management of ophthalmic patients having systemic illness along with internists improves overall outcomes and prevents morbidity in such patients.

\section{Abbreviations List}

$P U K$ : Peripheral ulcerative keratitis.

$C B C$ : Complete Blood Count.

$C M P$ : complete Metabolic Profile.
$A C E$ : angiotensin converting enzyme.

$B S$ : Behçet's syndrome.

\section{Declarations}

\section{Ethics Approval}

We had the patient's consent.

\section{Competing Interest}

We have no financial interest to disclose.

\section{Author's Contributions}

Belghmaidi sarah: conception of manuscript, data analysis El Baroudi taieb: bibliography.

Hajji ibtissam: reviewing.

Moutaouakil abdeljalil: supervision.

\section{References}

[1] Tavassoli S, Gunn D, Tole D, Darcy K. Peripheral ulcerative keratitis with corneal melt as the primary presentation in a case of human immunodeficiency virus. BMJ Case Rep. 2019 Feb 22; 12 (2). doi: 10.1136/bcr-2018-226936.

[2] Ploysangam P, Marie R. Perforating Peripheral Ulcerative Keratitis in Syphilis. Case Rep Ophthalmol. 2019 Aug 13; 10 (2): 267-273. doi: 10.1159/000501996.

[3] Lee WS, Choi YJ, Yoo WH. Rapid Progressive Peripheral Ulcerative Keratitis Associated with Longstanding Rheumatoid Arthritis. J Rheumatol. 2016 Oct; 43 (10): 19091910. doi: 10.3899/jrheum.160262

[4] Akdeniz N, Elmas ÖF, Karadağ AS. Behçet's Syndrome: A great imitator. Clin Dermatol. 2019 May - Jun; 37 (3): $227-$ 239. doi: 10.1016/j.clindermatol.2019.01.001.

[5] Hamuryudan V, Er T, Seyahi E, Akman C, Tüzün H, Fresko I, Yurdakul S, Numan F, Yazici H. Pulmonary artery aneurysms in Behçet syndrome. Am J Med. 2004 Dec 1; 117 (11): 86770. doi: 10.1016/j.amjmed.2004.05.027.

[6] Hatemi G, Christensen R, Bang D, et al. Recommendations for the management of Behcet's syndrome. Ann Rheum Dis. 2018 Jun; 77 (6): 808-818. doi: 10.1136/annrheumdis-2018213225 .

[7] Kitaichi N, Miyazaki A, Iwata D, Ohno S, Stanford MR, Chams H. Ocular features of Behcet's disease: an international collaborative study. Br J Ophthalmol. 2007 Dec; 91 (12): 1579-82. doi: 10.1136/bjo.2007.123554.

[8] Rohtagi J, Singal A. Ocular manifestations of Behcet's disease in indian patients. Indian J Ophthalmol. 2003 Dec; 51 (4): 309-13.

[9] Yong-Sok Ji, Kyung Chul Yoon. A rare case of peripheralulcerative keratitis associated with Behcet's disease. Int ophthalmol. 2014 Aug; 34 (4): 979-81.

[10] Dorot N, Coulon L, Poirier L, Brousse D, Mortemousque B, Verin P. Corneal ulcer and Behcet disease. J Fr Ophthalmol. 1995; 18 (2): 155-7. 
[11] Zeng J, Chen B. Severe primary ocular surface involvement in Behcet disease. Optom Vis Sci. 2014 Dec; 91 (12): e301-4. doi: 10.1097/OPX.0000000000000405.
[12] Jinagal J, Agarwal A, Negi A, Gupta G, Sharma V, Gupta PC, Ram J. Immune keratitis: An unusual primary presentation of neuro-Behçet's disease. Eur J Ophthalmol. 2019 Jul; 29 (4): NP5-NP8. doi: 10.1177/1120672118803534. 